\title{
Observatório
}

ISSN n² 2447-4266

Vol. 4, n. 3, maio. 2018

DOI: https://doi.org/10.20873/uft.2447-4266.2018v4n3p836

ENTRE LINHAS E

\section{ENTRELINHAS: a produção cultural em impressos de Imperatriz-MA}

IN THE LINES AND IN BETWEEN THE LINES: the cultural prodution in newspapers in Imperatriz-MA

ENTRE LÍNEAS Y ENTRELÍNEAS: la producción cultural em impresos de Imperatriz-MA

Roseane Arcanjo Pinheiro ${ }^{1,2}$

\section{RESUMO}

A pesquisa aborda a tematização da cultura em dois jornais da cidade de Imperatriz-MA: O Progresso e Capital. O objetivo foi apontar as temáticas mais recorrentes e compreender as representações contidas no material jornalístico a partir de conjunturas políticas, sociais e econômicas, nos 1970 e 1990. A partir dos conceitos de campo de Bourdieu (1997), de representação de Chartier (1990) e notícia, de Tuchman (1983), problematizamos o jornalismo e o agendamento da cultura. O estudo utilizou os recursos da análise de conteúdo e da pesquisa documental. Os impressos apresentaram uma cobertura do tema cultura, mas com pouco espaço. Concorrendo com notícias e manchetes de políticas local e nacional, os tópicos mais abordados no $O$ Progresso foram a literatura, a televisão e o cinema e no Capital, a música e literatura.

\footnotetext{
${ }^{1}$ Doutora em Comunicação Social (PUCRS). Mestrado em Comunicação Social (Universidade Metodista de São Paulo). Graduada em Comunicação Social (UFAM). Email: roseane arcanjo@yahoo.com.br.

${ }^{2}$ Endereço de contato com os autores (por correio): Universidade Federal do Maranhão Câmpus de Imperatriz - Rua Urbano Santos - Centro - Imperatriz/MA
} 


\section{Observatório}

ISSN n² 2447-4266

Vol. 4, n. 3, maio. 2018

DOI: https://doi.org/10.20873/uft.2447-4266.2018v4n3p836

PALAVRAS-CHAVE: Jornalismo; Cultura; Imperatriz-MA.

\section{ABSTRACT}

The research addresses the thematization of culture in two newspapers in the city of Imperatriz-MA: O Progresso e Capital. The objective was to identify the most recurrent themes and to understand the representations contained in journalistic material from political, social and economic conjunctures in the 1970s and 1990s. From the field concepts of Bourdieu (1997), from Chartier (1990) and news from Tuchman (1983), we problematize journalism and the scheduling of culture. The study used the resources of content analysis and documentary research. The Newspaper presented a coverage of the theme culture, but with little space. Competing with news and local and national policy headlines, the most topics touched in O Progresso were literature, television and film and in Capital, music and literature.

KEYWORDS: Journalism; Culture; Imperatriz-MA.

\section{RESUMEN}

La investigación aborda la tematización de la cultura en dos periódicos de la ciudad de Imperatriz - MA: O Progresso y Capital. El objetivo fue apuntar las temáticas más frecuentes y comprender las representaciones contidas en el material periodístico a partir de diferentes conyuncturas políticas, sociales e económicas, en los años 1970 y 1990. A partir de los conceptos de campo de Bourdieu (1997), de representación de Chatier (1990) y noticia de Tuchman (1983), problematizamos el periodismo y el agendamiento de la cultura. La investigación utilizó los recursos del análisis de contenidos y de la investigación documental. Los resultados aputan que O Progresso y Capital apresentaron unacobertura del tema cultura, pero con poco espacio. En competencia con noticias y manchetes de política local y nacional, los tópicos más abordados en O Progresso fueron la literatura, la televisón y el cine, el O Capital tuvo una cobertura centrada en la musica y literatura. 


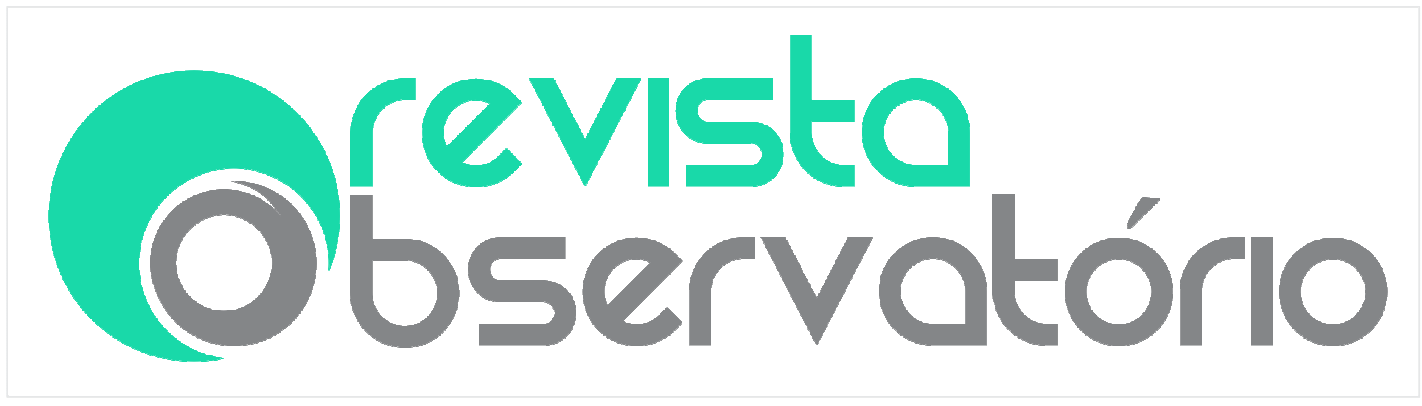

ISSN n² 2447-4266

Vol. 4, n. 3, maio. 2018

DOI: https://doi.org/10.20873/uft.2447-4266.2018v4n3p836

PALABRAS-CLAVE: Periodismo; Cultura; Imperatriz - MA.

Recebido em: 19.12.2018. Aceito em: 14.03.2018. Publicado em: 29.04.2018. 


\section{Observatório}

ISSN n² 2447-4266

Vol. 4, n. 3, maio. 2018

DOI: https://doi.org/10.20873/uft.2447-4266.2018v4n3p836

\section{Introdução}

Um campo social pode ser compreendido como um espaço abstrato capaz de se diferenciar do que está fora dele, com forças que operam interna e externamente. Adotamos, sobretudo, a lógica bourdiana na compreensão de campo.

\footnotetext{
Um campo é um espaço social estruturado, um campo de forças - há dominantes e dominados, há relações constantes, permanentes, de desigualdade, que se exercem no interior desse espaço - que é também um campo de lutas para transformar ou conservar esse campo de forças. Cada um, no interior desse universo, empenha em sua concorrência com os outros a força (relativa) que detém e que define sua posição no campo e, em consequência, suas estratégias (BOURDIEU, 1997, 57).
}

Com relativa autonomia o campo jornalístico se constitui, na perspectiva de Bourdieu (1997, p. 55), como um microcosmo com leis próprias, demarcado por uma posição no mundo global e de relações com outros microcosmos. O autor ao analisar a importância do jornalismo no mundo social destaca o poder dos veículos de comunicação para algo existir publicamente, a partir do monopólio exercido sobre os instrumentos de produção e divulgação das informações. "Não há discurso (análise científica, manifesto político etc.) nem ação (manifestação, greve etc) que, para ter acesso ao debate público, não deva submeter-se a essa prova da seleção jornalística [...]" (BOURDIEU, 1997, p. 67).

"A notícia é uma janela para o mundo", Tuchman (1983) utiliza essa metáfora ao criticar o enquadramento determinado pela mídia. A autora traz para o debate a notícia como uma instituição social, que apresenta ao público determinadas informações, elaboradas por profissionais sujeitos a uma rotina de trabalho. Assim, a rede de informação, verificada pela autora, exclui 


\section{Observatório}

ISSN n² 2447-4266

Vol. 4, n. 3, maio. 2018

DOI: https://doi.org/10.20873/uft.2447-4266.2018v4n3p836

acontecimentos, ao passo que favorece determinadas vozes dentro dos veículos jornalísticos em detrimento de outras. Wolf $(1987$, p. 198) corrobora ao acreditar que "Aqueles que detêm o poder econômico ou político podem, facilmente, ter acesso aos jornalistas e são acessíveis a estes; aqueles que não têm qualquer poder, mais dificilmente se transformam em fontes".

A tentativa de uma coordenação do tempo e do espaço por meio das organizações jornalísticas, conforme pontua Tuchman (1983), concretiza uma teia de facticidade reconhecida nas negociações entre instituições, os acordos entre os agentes das redes e as definições do que será ou não publicado. Traquina (2001, p. 98) complementa que se trata do "[...] tradicional quem, o que, quando, onde, como e por que do lead tradicional".

Para Bourdieu (1997), os jornalistas têm seus óculos particulares, com os quais selecionam fatos ao invés de outros e, a partir disso, constroem as notícias. Essas, segundo o autor, é um bem altamente perecível, e as novas notícias tornam-se ainda mais necessárias na proximidade da produção com o pólo comercial. Esses profissionais agem a partir de um monopólio de conhecimento, desta Traquina (2005) ao ressaltar a atuação dos jogadores - os jornalistas - e as notícias.

\footnotetext{
Para recapitular, a existência de um "campo" implica a existência de 1) um número ilimitado de "jogadores", isto é, agentes sociais que querem mobilizar o jornalismo como recurso para as suas estratégias de comunicação; 2) um enjeu ou prêmio que os "jogadores" disputam, nomeadamente as notícias; e 3) um grupo especializado, isto é, profissionais do campo, que reivindicam possuir um monopólio de conhecimentos ou saberes especializados, nomeadamente o que é notícia e sua construção (TRAQUINA, 2005, p. 27).
}

Ao refletir sobre as representações através do jornalismo, Fausto Neto (2011) aborda o formato singular de apresentação da realidade a partir das 


\section{Observatório}

ISSN n² 2447-4266

Vol. 4, n. 3, maio. 2018

DOI: https://doi.org/10.20873/uft.2447-4266.2018v4n3p836

operações enunciativas jornalísticas. Assim, os discursos jornalísticos, na concepção do autor

"[...] representam singularmente o mundo sobre o qual se reportam, também se apóiam em dimensões das linguagens para que assim possam exercitar o poder e suas respectivas forças de imposição e de limites de representações" (NETO, 2011, p. 42).

Portanto, verifica-se o poder do jornalismo em construir representações sobre outros campos sociais e ao mesmo tempo possui limites ao representar determinadas realidades e silenciar outras. Bourdieu (1997, p. 101) aponta a influência que os mecanismos do campo jornalístico exercem sobre a atuação dos jornalistas e nos diferentes campos de produção cultural, campo jurídico, campo literário, campo artísticos e campo científico.

Gadini (2005, p.3) observa que é necessário verificar o jornalismo em suas dimensões históricas e culturais, bem como enquanto "um campo marcado por relações de disputa e tensões com os demais campos que constituem a esfera pública...". Nesse sentido Chartier (1990, p.17) aborda as lutas de representações do mundo social pelos diferentes grupos que a forjam. Segundo o autor não existe discurso neutro nas percepções do social. Assim, é primordial verificar os locais de fala dos discursos enunciados para compreender as finalidades das representações.

Por isso, Chartier (1990) verifica a existência de enfrentamentos em que o desafio é baseado no poder e na dominação de cada grupo para impor a sua concepção de mundo social. Entre as estratégias utilizadas no jornalismo, a partir dessas concorrências, Fausto Neto (2011) menciona a utilização da linguagem, noticiabilidade e relações sócio organizacionais.

A principal competência midiática jornalística é de natureza discursiva na medida em que seus fundamentos de descrição/construção das realidades se fazem em meio às operações de linguagens e, ao 


\section{Observatório}

ISSN n² 2447-4266

Vol. 4, n. 3, maio. 2018

DOI: https://doi.org/10.20873/uft.2447-4266.2018v4n3p836

mesmo tempo em que os processos da noticiabilidade se estruturam, além de parâmetros sócio organizacionais, em presunções simbólicas, ou ainda, em referências e em transações que se realizam pelo capital das linguagens (FAUSTO NETO, 2011, p. 43).

Partindo desses pressupostos teóricos este artigo tem por objetivo analisar comparativamente as temáticas contidas no material jornalístico que aborda a produção de bens culturais em Imperatriz-MA, nas décadas de 1970 e 1990, que nesse mesmo período atravessa mudanças políticas, sociais e econômicas.

Os recursos adotados para a pesquisa foram a análise de conteúdo e a pesquisa documental. As edições de $O$ Progresso e Capital estavam disponíveis no Centro de Documentação do Jornalismo de Imperatriz (JOIMP), do Curso de Jornalismo da Universidade Federal do Maranhão, Campus Imperatriz, e digitalizadas na plataforma do acervo na internet. Para Bardin (1977, p.38), a intenção da análise de conteúdo é "a inferência de conhecimentos relativos à condição de produção (ou eventualmente, de recepção), inferência esta que recorre a indicadores (quantitativos ou não)".

Foram analisadas as primeiras edições disponíveis de cada jornal, totalizando : foram 3 meses de edição de cada um. Em O Progresso foram estudados primeiros doze números, o que correspondeu a 90 dias, sendo o jornal semanal. Quanto ao Capital, que era diário, adotou-se a semana construída que separou também doze edições nos primeiros meses disponíves de 1996.

A categoria definida para análise foi o tema, a partir da lista de códigos aplicados no levantamento quantitativo, elaborada por REIS (2017, p.123), autora da dissertação "A cultura nos diários maranhenses: uma análise editorial dos jornais O Estado do Maranhão, O Imparcial, Jornal Pequeno e O Progresso". 


\section{Observatório}

ISSN n² 2447-4266

Vol. 4, n. 3, maio. 2018

DOI: https://doi.org/10.20873/uft.2447-4266.2018v4n3p836

Os temas verificados foram Música, Cinema, Teatro/Dança; Artes Visuais; Literatura; Patrimônio Cultural; Patrimônio natural/Turismo; Gastronomia; Políticas Culturais; Televisão; Moda/comportamento; Tradições/Cultura Popular e Outro.

Esses impressos foram os que apresentaram maior tempo de circulação nas décadas citadas. O jornal O Progresso começa a circular em maio de 1970, tendo continuado até os dias atuais, enquanto o jornal. O Capital surge em 2 de setembro de 1994 e fecha suas portas em 2010 (REIS, 2011, p.44).

Os dois são jornais diários e descortinam conjuntas diferentes de uma cidade, que se transforma, entre os anos 70 e os anos 90, na segunda cidade com maior número de habitantes do Maranhão após ciclos econômicos, desencadeados principalmente pela construção da BR Belém Brasília e a expansão da atividade agrícola, a instalação de serrarias e siderúrgicas ligadas ao projeto Carajás. A cidade de Imperatriz salta de 80 mil em 1970, para mais de 220 mil em 1980, segundo dados do Censo, o que acarreta ocupação desordenada, problemas de infraestrutura e ampliação das desigualdades sociais (FRANKLIN, 2008, p. 143).

Nessa conjuntura de transformações, os impressos apresentam relevância ao dar sentidos às ações de sujeitos, governos e grupos sociais que estão na cena cultural, ao referendarem identidades, significados, hábitos e movimentações em um lugar onde estavam sendo operadas mudanças e em curso um ordenamento político e econômico a sinalizar representações sobre a realidade imediata, a apagar vozes e a conceder o poder de fala a determinados sujeitos. Os impressos se multiplicavam enquanto as primeiras emissoras de rádio ganhavam corpo (BRITO, 2016, p.41) e as emissoras de TV vão se 


\section{Observatório}

ISSN n² 2447-4266

Vol. 4, n. 3, maio. 2018

DOI: https://doi.org/10.20873/uft.2447-4266.2018v4n3p836

articulando às redes nacionais no começo dos anos 90 (PINHEIRO, SANTOS, 2016, p.179).

Sobe a quantidade de jornais nas ruas, repartições, igrejas, empresas, grupos estudantis e associações: nos anos 70 há registros de seis títulos de jornais, porém nos anos 80 esse volume sobre para 49 jornais. Nos anos 90 foram 67 impressos registrados e nos anos 2000 esse número continua a crescer: são 89 folhas de vários grupos sociais, com vida geralmente curta, diferentes matizes políticos, poucos exemplares, circulação débil e sem estrutura financeira para sustentar o meio (REIS, 2011, p.44). Porém, são acenos de uma sociedade com diferentes interesses em jogo e projetos de cidade a gerarem conflitos e/ou consensos.

\section{A Cultura no Jornal $O$ Progresso}

Com o lema "seminário noticioso e independente", o jornal $O$ Progresso surgiu em 3 de maio de 1970. De circulação semanal, aos domingos, no começo dos anos 70, passou por mudanças, como troca de proprietários e integrantes da equipe ao longo das décadas. Dos dois impressos estudados, é o único ainda em circulação.

Em seus primeiros anos, O Progresso tinha quatro páginas, sem divisões em editorias. A primeira página já trazia manchetes e notícias mais longas. $\mathrm{O}$ periódico também tinha colunas, como Resenha dominical, com pensamentos e piadas, e também a seção Desfile Social, com notas sobre viajantes e aniversariantes.

No material jornalístico publicado há uma predominância da política no conteúdo do jornal, o que nos deu pistas do projeto editorial do veículo. "Prefeito promete grande melhoramentos" foi a manchete principal da edição 


\section{Observatório}

DOI: https://doi.org/10.20873/uft.2447-4266.2018v4n3p836

pioneiro de 3 de maio de 1970, na primeira página, tendo uma foto do então prefeito Renato Moreira em destaque. No mês seguinte, no dia 13 de junho, a política ocupa várias chamadas na primeira página, como "O Globo de 25 garante Pedro Neiva", sobre a nomeação do ex-secretário de finanças do governo Sarney para o governo do estado, ou "Sarney ainda comanda", do dia 12 de julho, com a imagem do então ex-governador.

As notícias sobre Cultura aparecem com menos frequências nas páginas. No período estudado, apresentou 20 inserções, entre 3 de maio a 26 de julho de 1970, que são os primeiros três meses de circulação do jornal. Segue a tabela com os resultados:

Tabela 1 - Produção cultural no Jornal O Progresso

\begin{tabular}{|c|c|c|}
\hline Data & Titulo & Tema \\
\hline 03/mai & Não foi por acaso & Televisão \\
\hline 10/mai & Do valor ao rótulo & Literatura \\
\hline 10/mai & Remotismo & Literatura \\
\hline 10/mai & Educadora está na onda & Outro \\
\hline $17 /$ mai & Moderna sala de projeção cinematográfica & Cinema \\
\hline $31 /$ mai & Rádio Educadora transmitira do recinto da feira & Outro \\
\hline $31 /$ mai & A Voz do Brasil interrompida & Televisão \\
\hline 13/jun & Copa da agonia & Literatura \\
\hline 21/jun & Sem cerimônia & Literatura \\
\hline 28/jun & Cristo Vive revive folclore & $\begin{array}{c}\text { Tradições/Cultura } \\
\text { Popular }\end{array}$ \\
\hline 5/jul & Professora escreve história de Imperatriz & Literatura \\
\hline $5 / \mathrm{jul}$ & Livro sobre o Maranhão & Literatura \\
\hline 5/jul & Crônica $\mathrm{O}$ assalto & Literatura \\
\hline 12/jul & Vamos ter agora: o Cine Caiçara & Cinema \\
\hline 12/jul & Crônica A lambreta de Kalm Heleuteros & Literatura \\
\hline 12/jul & Antropóloga volta a Imperatriz & Políticas culturais \\
\hline
\end{tabular}




\section{Observatório}

ISSN n² 2447-4266

Vol. 4, n. 3, maio. 2018

DOI: https://doi.org/10.20873/uft.2447-4266.2018v4n3p836

\begin{tabular}{|l|l|l|}
\hline 19/jul & Crônica Incorreção monetária & Literatura \\
\hline $26 /$ jul & TV em Imperatriz & Televisão \\
\hline $26 /$ jul & Crônica Brasilino e os porcos queixadas & Literatura \\
\hline 26/jul & Rosinha & Literatura \\
\hline
\end{tabular}

Os temas literatura, televisão e cinema estão os temas mais recorrentes entre as notícias de cultura. A literatura apresentou onze textos publicados, em sua maior parte crônicas, assinadas por Kalm Heleuteros, Jotaemê ou Mario Mazini. Abordam cenas do cotidiano, a relação entre vizinhos, perda de objetos, o torcedor e a copa de 70, mas não trazem aspectos da vida em Imperatriz especificamente. E também são os únicos textos com identificação dos autores. São geralmente são longos e sem ilustrações.

O lançamento de dois livros, um da professora Edelvira Barros, informado no dia 5 de julho de 1970, e da professora Rosa Mochel, sobre geografia econômica, chama a atenção. Mas há razões políticas relacionadas. $O$ jornal aponta que "com o intuito de difundir a verdadeira história de Imperatriz, tão pouco conhecida por nossos estudantes e pela população em geral", o prefeito Renato Moreira incumbiu a educadora da tarefa de lançar a publicação, que " a prefeitura irá mandar publicar". Uma ação governamental tem relevo na outra notícia, "Livro sobre o Maranhão", porque, "sob os auspícios do estado será publicado e brevemente entregue às livrarias o livro CONHEÇA O MARANHÃO (grifo do jornal), de autoria da professora Rosa Mochel". O jornal enfatiza a importância do livro, pois focalizará "a geografia econômica do estado e admite-se inclusive a sua possibilidade de adoção nas escolas primárias". 


\section{Observatório}

ISSN n² 2447-4266

Vol. 4, n. 3, maio. 2018

DOI: https://doi.org/10.20873/uft.2447-4266.2018v4n3p836

A temática "Televisão" teve duas inserções, como o título "Não foi por acaso", do dia 3 de maio, sobre um programa de TV que abordou a comemoração em Portugal da independência do Brasil. São textos geralmente sem autoria, o que aconteceu na maioria das notas e notícias sobre a cena cultural. Os conteúdos que trazem a televisão como tema envolvem ainda a chegada da tecnologia na cidade e a movimentação das autoridades para viabilizar o intento, como a seguir.

O coronel-engenheiro Antonio Ribeiro Sêco, um dos diretores da EMBRATEL, esteve em Imperatriz em viagem de inspiração dos serviços de instalação da empresa neste setor.

Em sua curta permanência, o Cel. Solicitou à prefeitura a doação de terreno, dentro da cidade, para a edificação de 4 casas destinadas à residência de técnicos da EMBRATEL, que aqui se encarregarão da torre e demais instalações (O Progresso, 26 de julho de 1970, p.1).

O cinema é outra novidade da indústria cultural na cidade que recebeu também duas inserções. Noticiam as novas salas de cinema e detalham como serão os empreendimentos. O destaque era a modernização, o conforto, a oferta de um número maior de assentos e a estrutura moderna dos projetores. No dia 17 de maio de 1970, com a chamada "Moderna sala de projeção cinematográfica", O Progresso notícia a chegada em breve de "um novo e luxuoso cinema de propriedade de grupo empresarial da vizinha cidade de Marabá, a cuja frente está o sr. Iran Bichara". E a inauguração estava prevista para ser feitas em 120 dias.

A notícia sobre o cine Caiçara prometia mais novidades, na capa da edição de 12 de julho. $O$ jornal informou que existiam três edificações na cidade destinadas ao cinema, aparentemente do mesmo grupo de Marabá: "a 


\section{Observatório}

ISSN n² 2447-4266

Vol. 4, n. 3, maio. 2018

DOI: https://doi.org/10.20873/uft.2447-4266.2018v4n3p836

construção de três modernos prédios destinados à exibição de filmes". "Uma dessas encontra-se em fase adiantada e fica junto ao antigo campo de futebol" .

No item "Outro", classificamos as notícias relacionadas chegada de rádios e a programação delas. A primeira emissora será implantada anos depois, em 1978 pelo empresário Moacyr Spósito (BRITO, 2014, p. 20), com a proposta de entretenimento e jornalismo, porém já circulam em 1970 as iniciativas para operacionalizar os projetos. Na edição do dia 10 de maio, a informação parte do vereador pela Arena, Leôncio Pires Dourado, "conceituado político", que foi a fonte principal. "Brevemente Imperatriz contará com poderosa emissora de rádio-difusão, com equipamento moderno, prédio próprio e alcance médio de 250 kilometros".

Uma outra notícia sobre a Rádio Educadora, que estava sendo implantada na cidade, é publicada em 31 de maio, "Rádio Educadora transmitirá do recinto da feira". A rádio, segundo Leôncio Pires, mais uma vez citado, vai transmitir a exposição agropecuária que estava ocorrendo na cidade naquele período. Terá "programas de diversão e de noticiário das atividades do conclave, além de programação de utilidade pública".

As temáticas como "Tradições e cultura popular" e "Políticas culturais" são as mais raras, cada uma apresentou uma inserção. Foram uma notícia sobre a apresentação de bumba-meu- boi em uma escola, uma expressão da cultura popular, anunciada no dia 28 de junho, e a outra foi uma palestra da antropóloga Francisca Isabel Vieira sobre desenvolvimento regional no Rotary, noticiada em 12 de julho pelo jornal O Progresso. 


\section{Observatório}

ISSN n² 2447-4266

Vol. 4, n. 3, maio. 2018

DOI: https://doi.org/10.20873/uft.2447-4266.2018v4n3p836

\section{A Cultura no Jornal Capital}

Ao todo, foram analisadas doze edições do jornal Capital referentes ao meses de janeiro, fevereiro e março de 1996. O jornal era veiculado de terça a domingo, desse modo foram escolhidos quatro publicações por mês, os dias selecionados foram: 09 de janeiro (terça-feira), 19 de janeiro (sexta-feira), 24 de janeiro (quarta-feira), 28 de janeiro (domingo), 08 de fevereiro (quinta-feira), 17 de fevereiro (sábado), 23 de fevereiro (sexta), 27 de fevereiro (terça-feira), 03 de março (domingo), 09 de março (sábado), 21 de março (quinta-feira) e 27 de março (quarta-feira). Desse modo, cada dia da semana foi contemplado com duas inserções na coleta, resultando na tabela a abaixo.

Tabela 2 - Produção cultural no Jornal Capital

\begin{tabular}{|c|c|c|}
\hline Data & Titulo & Tema \\
\hline 09/jan & Acertado & Música \\
\hline 09/jan & Em nome da arte: A cultura do índio & $\begin{array}{c}\text { Tradições e Cultura } \\
\text { Popular }\end{array}$ \\
\hline 09/jan & $\begin{array}{l}\text { A Última Moda: Barriguinha de Fora, } \\
\text { Umbiguinho de Fora!!! }\end{array}$ & $\begin{array}{c}\text { Moda e } \\
\text { Comportamento }\end{array}$ \\
\hline 19/jan & $\begin{array}{l}\text { Últimas: "Xoxoteiros" participam do Carnaval } \\
\text { do "Than" }\end{array}$ & Teatro/Dança \\
\hline 19/jan & Curiosidades Linguisticas Regionais & Patrimônio Cultural \\
\hline 19/jan & $\begin{array}{l}\text { Lições, com o tempo comtemporâneidade do } \\
\text { não coetâneo }\end{array}$ & Literatura \\
\hline 19/jan & Curtas \& Boas & Música \\
\hline 19/jan & $\begin{array}{l}\text { Em nome da arte: Crise e reconstrução do } \\
\text { Cinema Latino-Americano }\end{array}$ & Cinema \\
\hline 24/jan & Luz da Natureza & Literatura \\
\hline 24/jan & Carnaval: samba do calote & Música \\
\hline 24/jan & O Bom Ladrão & Literatura \\
\hline 24/jan & Em nome da arte - Desfile em Imperatriz & Teatro/Dança \\
\hline 24/jan & Uma nova doença: a "Cropofilia" & Literatura \\
\hline
\end{tabular}




\section{Observatório}

ISSN n² 2447-4266

Vol. 4, n. 3, maio. 2018

DOI: https://doi.org/10.20873/uft.2447-4266.2018v4n3p836

\begin{tabular}{|c|c|c|}
\hline 28/jan & Show & Música \\
\hline 28/jan & Cancelado & Música \\
\hline 28/jan & A Bahia é aqui & Música \\
\hline 28/jan & Só Tristeza & Música \\
\hline 28/jan & Em nome da arte: A Cultura do Aurélio & Literatura \\
\hline 28/jan & Colecionador de Literatura & Literatura \\
\hline $08 / \mathrm{fev}$ & Amor Declarado & Literatura \\
\hline $08 / \mathrm{fev}$ & Largarda Carnavalesca & Música \\
\hline $08 / \mathrm{fev}$ & Em nome da Arte: O Carnaval do Lava Pratos & Música \\
\hline $08 / \mathrm{fev}$ & Tchan Tchan & Música \\
\hline $08 / \mathrm{fev}$ & A Série do Tempo & Literatura \\
\hline $17 / \mathrm{fev}$ & Começa hoje o Carvanal do Tchan & Música \\
\hline $17 / \mathrm{fev}$ & Clima Carnavalesco & Música \\
\hline $17 / \mathrm{fev}$ & Ipê Clube & $\begin{array}{c}\text { Patrimônio } \\
\text { Natural/Turismo }\end{array}$ \\
\hline $17 / \mathrm{fev}$ & Em nome da arte: Um gole de cachaça & Gastronomia \\
\hline $17 / \mathrm{fev}$ & Carnaval é Vapt-Vupt & Música \\
\hline $17 / \mathrm{fev}$ & Carnabaixinho & Música \\
\hline $17 / \mathrm{fev}$ & PRF realiza Operação Carnaval & Outros \\
\hline $17 / \mathrm{fev}$ & Portaria regulamenta Carvanal & Outros \\
\hline $23 / \mathrm{fev}$ & Carnaval do Conor & Música \\
\hline $23 / \mathrm{fev}$ & Folia Geral & Música \\
\hline $23 / \mathrm{fev}$ & Grupo Difusora parabeniza Conor & Música \\
\hline $23 / \mathrm{fev}$ & Sistema Tucanu's em festa & Música \\
\hline $23 / \mathrm{fev}$ & Baile da Ressaca & Música \\
\hline $23 / \mathrm{fev}$ & Comemoração & Música \\
\hline $23 / \mathrm{fev}$ & Juçara no prejuízo & Música \\
\hline $23 / \mathrm{fev}$ & Caprichosos e Tradição são rebaixados & Teatro/Dança \\
\hline $23 / \mathrm{fev}$ & Olinda e Rio. Música & Música \\
\hline $23 / \mathrm{fev}$ & Filme & Cinema \\
\hline $23 / \mathrm{fev}$ & Só Cinzas & Música \\
\hline $27 / \mathrm{fev}$ & Lévi-Straus mostra SP & Literatura \\
\hline $27 / \mathrm{fev}$ & Bruxa abré baú & Literatura \\
\hline $27 / \mathrm{fev}$ & "Street Figther" chega às telas & Cinema \\
\hline $27 / \mathrm{fev}$ & AlL estimula a cultura & Políticas Culturais \\
\hline
\end{tabular}




\section{Observatório}

ISSN n² 2447-4266

Vol. 4, n. 3, maio. 2018

DOI: https://doi.org/10.20873/uft.2447-4266.2018v4n3p836

\begin{tabular}{|r|l|c|}
\hline $27 / \mathrm{fev}$ & Dos tempos do Biotônico & Literatura \\
\hline $27 / \mathrm{fev}$ & Dia da Mulher & Políticas Culturais \\
\hline $03 / \mathrm{mar}$ & O Quatrilho & Cinema \\
\hline $03 / \mathrm{mar}$ & O Quatrilho no Oscar & Cinema \\
\hline $03 / \mathrm{mar}$ & Lava Pratos & Música \\
\hline $03 / \mathrm{mar}$ & Retrospectiva & Música \\
\hline $03 / \mathrm{mar}$ & Entidades comemoram o Dia da Mulher & Políticas Culturais \\
\hline $09 / \mathrm{mar}$ & Fantasia do Amor & Literatura \\
\hline $09 / \mathrm{mar}$ & Infantil & Televisão \\
\hline $21 / \mathrm{mar}$ & Culpa, graça e cobrança & Literatura \\
\hline $21 / \mathrm{mar}$ & Lançados CD's de Sílvio Caldas & Música \\
\hline $21 / \mathrm{mar}$ & Reconhecendo o talento do artista brasileiro & Música \\
\hline $21 / \mathrm{mar}$ & Por mares nunca antes navegados & Literatura \\
\hline $21 / \mathrm{mar}$ & E Fabiano se mostrara desentendido & Literatura \\
\hline $21 / \mathrm{mar}$ & Corpo Esquelético & Literatura \\
\hline $21 / \mathrm{mar}$ & Fez-se da vida uma aventura errante & Literatura \\
\hline $21 / \mathrm{mar}$ & Multidão em busca do objetivo escondido & Literatura \\
\hline $27 / \mathrm{mar}$ & Carnaval do Lava Pratos anima imperatrizenses & Música \\
\hline $27 / \mathrm{mar}$ & Lava Pratos deve levar multidão a Beira Rio & Música \\
\hline
\end{tabular}

Por meio da análise, encontramos 66 inserções de temáticas relativas a cultura no jornal Capital. O diário teve a presença de 29 temas classificados como "Música", pois se tratavam de matérias sobre show, festas, cantores e bandas. Esse número revela que o tratamento dado a cultura pelo impresso esteve relacionado, principalmente, a agenda cultural da cidade. Importante ressaltar que o período carnavalesco elevou esta categoria temática devido o mês de fevereiro conter na análise, mas não somente isso. $O$ jornal integrava o Grupo Tucanu's de Comunicação e este estava organizando o "Carnaval do Tchan", um evento comandado e apresentado pelo diretor-presidente do Sistema, Conor Farias. 


\title{
Observatório
}

ISSN n² 2447-4266

Vol. 4, n. 3, maio. 2018

DOI: https://doi.org/10.20873/uft.2447-4266.2018v4n3p836

\begin{abstract}
Um verdadeiro batalhão de repórteres, cinegrafistas e apresentadores já está preparado para entrar em campo. Vai levar todas as informações do Carnaval de 1996 até os telespectadores da TV Capital, Canal 5, Rádio Capital AM e Jornal Capital (Capital, 17 de fevereiro de 1996).
\end{abstract}

As duas principais colunistas da época, Juçara Cerqueira (Coluna Capital Social) e Soraya Luiza (Coluna Sociedade em Expressão) também divulgaram bastante o carnaval organizado pelo veículo por meio de 'notinhas" antes e pós-evento. Chama atenção que, alinhado as publicações da festa, foram realizadas inserções de publicidade do "Carnaval do Tchan" ocupando meia página e páginas inteiras do veículo. Embora o evento carnavalesco seja de caráter cultural, ele ganhou contorno de assunto policial, por isso o tema foi classificado como "Outros" em duas ocasiões do dia 17 de fevereiro de 1996, conforme mostra a tabela 1.

A "Literatura" foi o segundo tema mais abordado no veículo com 18 inserções. Trata-se, principalmente, não de notícias sobre a Literatura, mas de contos, crônicas e poesias como é possível observar, por exemplo, nos títulos: "Amor Declarado", "Fantasias do Amor" e "Culpa, graça e cobrança". A presença de tópicos literários começou a crescer no veículo a partir do mês de março quando surgiu a editoria de "Literatura". Esta situação é possível ser observada no dia 21 de março quando há cinco menções a Literatura, trata-se de textos de autores consagrados como Luiz Vaz de Camões, Graciliano Ramos e Vinicius de Morais junto a dois textos do jornalista do próprio veículo, Raimundo Primeiro. Alinhado a informação do surgimento dessa nova editoria, observou-se que em dois dias da coleta do mês de março, especificamente em 03 e 09 de março a editoria Cultura/Tendência/Debate foi identificada apenas como Tendência/Debate. É possível inferir que essa alteração influiu na produção de 


\title{
Observatório
}

ISSN n² 2447-4266

Vol. 4, n. 3, maio. 2018

DOI: https://doi.org/10.20873/uft.2447-4266.2018v4n3p836

material sobre cultura, pois justamente nestas datas o jornal publicou poucas informações culturais.

A categoria temática "Cinema" possui cinco ocorrências no veículo. Tratase de referências a filmes de âmbito internacional como "Street Figther" e nacional como "O Quatrilho". Mas não há informações se o filme será exibido em Imperatriz e em qual cinema, mas apenas a sinopse das obras cinematográficas. Uma matéria buscou abordar a crise e reconstrução do Cinema Latino-Americano, porém é possível deduzir que se tratava de material de agência pela matéria não conter assinatura e ter caráter analítico. Além disso, o Capital, no expediente afirma que recebia material noticioso das Agências Estado e Voz América.

"Políticas Culturais" e "Teatro/Dança" tiveram cada tema três inserções. Em Políticas Culturais é possível observar uma das únicas matérias produzidas, de fato, sobre Cultura pelo veículo. O texto "AlL estimula a cultura", assinado pelo diretor de Jornalismo, Frederico Luiz é praticamente uma moção de aplausos à Academia Imperatrizense de Letras pelos serviços prestados a cidade com destaque para o trabalho intelectual dos membros:

\begin{abstract}
A AIL, presidida pelo teólogo e escritor Vitor Milesi, participa da vida da cidade. Interferindo no cotidiano, consegue deixar sua marca no município. Os imortais de Imperatriz, nesse aspecto particular, possuem uma característica que serve de exemplo para o Brasil. Os intelectuais daquela casa, deixam o diletantismo de lado, e estão arregaçando as mangas para defender a cultura da cidade. Tudo isso feito, sem barreiras do regionalismo ou de qualquer "ismo". É assim que estimula a produção cultural (Capital, 27 de fevereiro de 1996).
\end{abstract}

Embora o texto não explore a instituição com fontes e dados, trata-se de uma entidade de organização do setor cultural que desenvolve políticas 


\section{Observatório}

DOI: https://doi.org/10.20873/uft.2447-4266.2018v4n3p836

culturais para cidade. Junto a essa matéria, outras duas sobre ações de promoção ao dia da Mulher foram encaixadas na temática de "Políticas Culturais". Sobre teatro e dança, das três matérias nenhuma fala de apresentação teatral, mas sim de desfiles de escolas de carnaval tanto local quanto nacional. Ressalta-se que nestes casos, o enfoque do material foi de fato a apresentação e espetáculo das escolas de Samba, sem destaque para parte musical do evento.

Outras categorias temáticas tiveram apenas uma inserção no veículo entre as doze edições, são elas: Gastronomia, Moda e Comportamento, Patrimônio Cultural, Patrimônio Natural/Turismo, Televisão e Tradições e Cultura Popular. Estes dados reforçam que os bens culturais da cidade estão centrados, principalmente na agenda de eventos musicais. Observa-se que nestas categorias o assunto tratado era referente à gastronomia, programa de televisão e patrimônios culturais de outras localidades e não da cidade de Imperatriz, lugar de cobertura do veículo. As categorias "Artes Visuais" e "Patrimônio Cultural" não foram encontradas no impresso.

\section{Conclusões}

O jornal O Progresso, fundado em Imperatriz no começo nos anos 70, aborda de forma tímida a tema Cultura e as notícias relacionadas a esse campo. A partir da análise de noventa dias de edições, foram encontradas 20 inserções de conteúdos relacionados a textos literários, lançamentos de livros, salas de cinema, programação radiofônico e eventos culturais em escolas e organizações.

Concluímos que no jornal $\mathrm{O}$ Progressso não priorizou o noticiário cultural e as poucas matérias publicadas não trazem os grupos, sujeitos e 


\section{Observatório}

ISSN n² 2447-4266

Vol. 4, n. 3, maio. 2018

DOI: https://doi.org/10.20873/uft.2447-4266.2018v4n3p836

movimentos relacionados à cidade de Imperatriz. Há nos conteúdos encontrados maior relação com temas ligados à indústria cultural, como televisão, cinema e rádio, e a publicações de textos literários que não abordam raramente a cultura local e suas expressões regionais.

A notícia sobre cultura no jornal Capital, em sintonia com as ideias de Tuchman (1983) poderia ser considera como uma janela entreaberta. Além de pouca produção, o material do veículo é direcionado para bens culturais produzidos pelo próprio veículo como ficou evidenciado na cobertura do "Carnaval do Tchan". Como a maioria de textos presentes no jornal é referente a Música e Literatura, é possível perceber a quase inexistência de vozes para debater cultura na cidade, pois as notícias relacionadas a Música tratam basicamente da agenda de shows, ora limitadas a notas e as referentes a Literatura englobam apenas a publicações de textos, também se apuração da produção literária.

Ressalta-se que o ano de 1996 foi um ano incomum para política de Imperatriz, pois o prefeito era um interventor do Governo Estadual provisoriamente em exercício. A instabilidade política do município tomou espaço das manchetes e agendou o jornal quase diariamente com notícias sobre as incertezas políticas da cidade. Desse modo, consideramos que a presença de 66 inserções de cultura no impresso não refletiu a produção de cultural da cidade.

\section{Referências}

BARDIN, Laurence. Análise de Conteúdo. São Paulo: Martins Fontes, 1977. 


\section{Observatório}

ISSN n² 2447-4266

Vol. 4, n. 3, maio. 2018

DOI: https://doi.org/10.20873/uft.2447-4266.2018v4n3p836

BOURDIEU, Pierre. Sobre a Televisão. Rio de Janeiro: Jorge Zahar, 1997.

BRITO, Nayane Cristina Rodrigues de. O que eles lembram? Rádio Imperatriz e a memória dos ouvintes. In: BRITO, Nayane Cristina R. de; REIS, Rodrigo Nascimento; PINHEIRO et al. Jornalismo, mídia e sociedade: as experiências na Região Tocantina. São Luís: Edufma, 2016.

Imperatriz: Haley AS, 2014.

Ondas da memórias: a pioneira Rádio Imperatriz.

CHARTIER, Roger. A história cultural: Entre práticas e representações. Lisboa:

Difel/Bertrand Brasil,1990.

FRANKLIN, Adalberto. Apontamentos e fontes para a história econômica de Imperatriz. Imperatriz: Etica, 2008.

GADINI Sérgio Luiz. Dilemas da Pesquisa no Jornalismo Contemporâneo: da abrangência midiática à ausência de métodos específicos de investigação. Trabalho apresentado no III Encontro Nacional de Pesquisadores em Jornalismo 27 a 29 de Novembro de 2005. Florianópolis / Sc. Disponível em: <http://sbpjor.kamotini.kinghost.net/sbpjor/admjor/arquivos/iiisbpjor2005__ci_-_sergio_luiz_gadini.pdf $\geq$. Acessado em 30 de março de 2015.

NETO, António Fausto. 0 Jornalismo e os limites da representação. Caleidoscópio: Revista de Comunicação e Cultura, n. 5/6, julho, 2011. ISSN 1645-2585. Disponível em: <http://revistas.ulusofona.pt/index.php/caleidoscopio/article/view/2240>. Acesso em 08 outubro de 2017.

PINHEIRO, Roseane A, SANTOS, Paula de Társsia de Sousa. A TV Difusora Sul: as práticas jornalísticas na década de 90. In: BRITO, Nayane Cristina R. de; REIS, Rodrigo Nascimento et al. Jornalismo, mídia e sociedade: as experiências na Região Tocantina. São Luís: Edufma, 2016.

REIS, Thays Assunção. Imprensa em Imperatriz-MA: uma proposta de periodização dos jornais impressos (1932-2010). Monografia (Curso de Jornalismo). Universidade Federal do Maranhão, Imperatriz, 2011.

A cultura nos diários maranhenses: uma análise editorial dos jornais $O$ Estado do Maranhão, O Imparcial, Pequeno e O Progresso. 


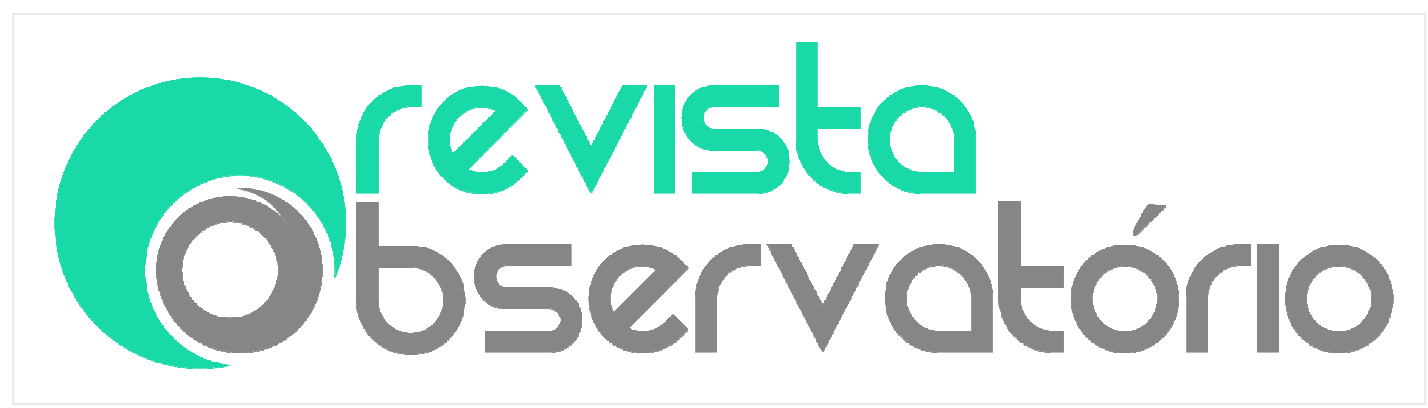

ISSN n² 2447-4266

Vol. 4, n. 3, maio. 2018

DOI: https://doi.org/10.20873/uft.2447-4266.2018v4n3p836

Dissertação (Mestrado em Comunicação Social) - Universidade estadual de Ponta Grossa, 2017.

TRAQUINA, Nelson. Teorias do jornalismo: porque as notícias são como são. Florianópolis: Insular, 2005.

TUCHMAN, G. La producción de la noticia: estudio sobre la construcción de la realidad. Barcelona: Editorial Gustavo Gili, 1983.

WOLF, Mauro. Teorias das comunicações. Lisboa: Editora Presença, 1987. 